\title{
The Effect of the Positive and the Negative Evidences in Learning English 'to' with Manner-of-Motion to Goal Constructions by L1 Saudi Arabic Speakers
}

\author{
Hanan Mohammed Kabli ${ }^{1 \& 2}$ \\ ${ }^{1}$ English Department, King Abdulaziz University, Rabigh, Saudi Arabia \\ ${ }^{2}$ English Language Institute, Jeddah University, Jeddah, Saudi Arabia \\ Correspondence: Hanan M. Kabli, English Department, King Abdulaziz University, Rabigh, Saudi Arabia. \& \\ English Language Institute, Jeddah University, Jeddah, Saudi Arabia. E-mail: hmkabli@kau.edu.sa or \\ hmkabli@uj.edu.sa
}

Received: April 12, 2020

Accepted: May 13, 2020

Online Published: May 15, 2020

doi: $10.5539 /$ elt.v13n6p20

URL: https://doi.org/10.5539/elt.v13n6p20

\begin{abstract}
The present study investigates the effect of the first language (L1) on learners by using the negative and the positive evidence in the classrooms while teaching English directional prepositions such as 'to' and 'into'. It is assumed that Arabic has two versions of 'to'. It has the directional interpretation without boundary-crossing which is equivalent to the English 'to'; whereas, it also denotes a similar interpretation to English directional preposition 'into' which is unavailable in Arabic and involves boundary-crossing. The study considers two groups to examine the effect of the overlaps, who are at an intermediate stage of development; the experiment group (E.G.) and the control group (C.G.). The control group is the base to measure the effectiveness of the treatments on the experiment groups' judgments. Hence, an Acceptability Judgment Task is devised to elicit participants' judgments on the task items in the pretest and the posttest. Results show clear advantage of the negative evidence in the experiment group's performance in the posttest in learning 'to' with and without boundary-crossing. There is a difference in the experiment group's performance in the posttest in learning 'into' with the boundary-crossing event after receiving the positive evidence. Similarly, a difference was observed in the experiment group's judgment with those of the control group in the comparison between 'to' and 'into' with the boundary-crossing event in the posttest.
\end{abstract}

Keywords: boundary-crossing, first language (L1), negative evidence, positive evidence, subset, superset

\section{Introduction}

The studies of argument structures in the first and second languages have increased the interest in the field of Second Language acquisition (SLA). Previous studies have mainly focused on the effect of over-/under-generalization based on L1 property of dative alternation (Juffs, 2000; White 2003; White 1987; White 1991; Mazurewic, 1984). Similarly, other studies examine the acquisition of causative alternation by different L1s (Moore, 1994; Montrul, 1997; Cabrera \& Zubizarreta, 2003; Cabrera \& Zubizarreta, 2005; Rezai \& Ariamanesh, 2011). Similarly, White (1991) examined the under/over-generalization in the relation to superset and subset on Anglophone children learning French. The results suggested that the overlap relationship possesses learnability problems for the L2 learners to adopt two type of scenarios. The first scenario is when the L1 is the subset and the L2 is the superset. This type of overlap leads L2 learners to undergeneralize (restrict) the L2 grammar to that of the L1. In this situation, White (1991) claimed that the L2 learners need to adopt the conservative position. It fails to notice that L2 has a range of structures that are absent in the L1 (Figure 1). On the other hand, when L1 is the superset and the L2 is the subset, L2 learners tend to overgeneralize L2 grammar because the L2 data matches the L1 (Figure 2). Therefore, nothing in the input is likely to inform L2 learners that certain constructions are impossible in L2.

The present study aims to explore the potential effect of the overlap between L1 and L2 in learning of the English directional preposition 'to' and 'into' with manner-of-motion verbs among the Saudi Arabic speakers. It is assumed that this overlap will cause learnability problems to L2 learners. Therefore, examining the overlap between English and Arabic in the term of realizing these constructions would allow identifying the role of the first language and observing the development after receiving the treatment. When L1 is the subset and L2 is the superset, this overlap leads L2 learners to undergeneralize the L2 grammar. Thus, teachers should adopt the 
positive evidence approach in their classrooms. However, L2 learners tend to overgeneralize L2 grammar, when the languages are in a reverse position. In this situation, the negative evidence technique is suitable treatment in the classrooms to restrict L2 learners' grammar.

Based on the proposal of White (1991), Saudi Arabic learners will treat the English 'to' as it is in their L1 at the initial stage of development. Therefore, it is expected that both groups of L2 learners will allow 'to' as denoting both $\pm \mathrm{B}$-C interpretations in the pretest. Consequently, learners require exposure to negative evidence to obstruct the overgeneralization of the L1 grammar. If the negative evidence allows the limiting of the L1 grammar, then it is expected that the experiment group learners will avoid over usage of the directional preposition 'to' in the posttest. On the contrary, Saudi Arabic will be the subset and English will be the superset in relation of the directional B-C preposition 'into'. Since this preposition is unavailable in Arabic, the positive evidence would permit L2 learners to broaden their L2 grammar. Therefore, it is expected that the performance of the treatment group would be better in the posttest, as compared to pretest. The undergeneralization of the L2 grammar will be dissolved after the exposure. The present study aims to answer the following research questions;

1. If the L2 is a subset and the L1 is the superset, will both groups of Saudi Arabic speakers overgeneralize the English 'to' as denoting both $\pm \mathrm{B}-\mathrm{C}$ interpretations in the pretest as it is in their L1?

2. Will negative evidence help the E.G. to restrict their interlanguage grammar to the L2 grammar in case of 'to' with B-C in the posttest?

3. Will positive evidence enable the E.G. to broaden the L2 grammar in learning of 'into' with B-C in the posttest?

4. Will there be a difference between the judgments of the two groups in 'to' and 'into' with B-C event in the posttest after the E.G. received the positive evidence?

In light of previous researches on argument structures, the present study aims to investigate the Arabic directional preposition 'to' in relation to manner-of-motion to goal constructions. Previously, most of the studies in the field of Second Language Acquisition have examined the effect of either the negative or the positive evidence; however, only few studies have investigated the role of both evidences in the classrooms. This study determines the effect of both treatments in learning L2 argument structures in relation to manner-of-motion constructions. This is the first study to address the relationship of the overlap between L1 and L2 using animation clips. Many studies recommend both evidences as treatments for generalization, but never actually test these treatments in the classroom. This study examines if learners are successful in learning the structures based on the given treatments.

\section{Literature Review}

White (1991) suggested a treatment to broaden L2 learners' grammar via positive evidence, if L2 learners maintain the position of the first scenario. Positive evidence is that the information about which strings of words are similar to grammatical sentences in the ambient language (Marcus, 1993). However, negative evidence is a suitable option to limit L2 learners' grammar and overcome of the overgeneralization. According to Jabbari and Niroomizadeh (2008), negative evidence provided information to learners about what is not possible in the target language (White, 1990; Long, 1996; White, 2003). It can be provided preemptively (e.g., through an explanation of grammar rules), or reactively (e.g., through error correction). Reactive negative evidence highlighted the differences between the target language and a learner's output and as such is often described as negative feedback' (Jabbari \& Niroomizadeh). In contrast, positive evidence is usually in the form of what the learners hear or read unconsciously in the classroom. Generally speaking, learners are exposed to this type of evidence in the course of learning any given language.

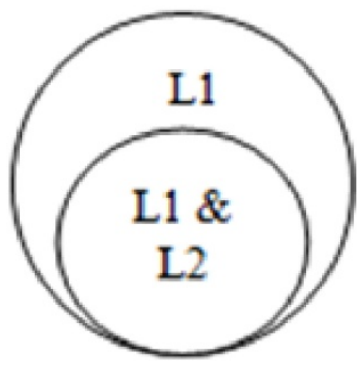

Figure 1. L1 superset - L2 subset relationship 


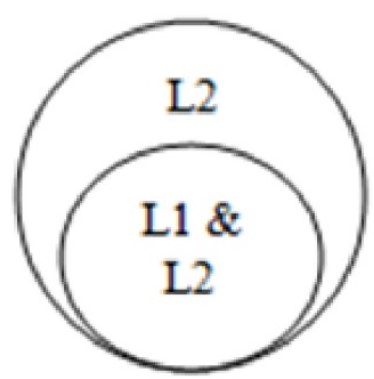

Figure 2. L2 Superset - L1 subset relationship

White (1991) examined dative alternation in the English and French languages. English allows prepositional dative construction, such as (1a). In addition, it allows double-object dative alternation, as in (1b).

1. a. John gave the book to Mary

b. John gave Mary the book

On the contrary, French allows prepositional but not the double-object dative construction as in the following example (2).

2. a. Jean a donné le livre à Marie

b. * Jean a donné Marie le livre

As a result, French maintains the subset position of English dative alternation. White (1991) showed that English speakers accept double-object construction as it is in their L1, due to absence of exposure to this construction in the input. English speakers are unaware that this construction is impossible in French, as the French speakers learn the grammaticality of the English double-object dative, despite the fact that this argument construction is impossible in French. As per White's claim, the difference between English and French speakers is a result of the availability of this construction in the input. In other words, French speakers are exposed to this construction in the input via positive evidence. The positive evidence enables French speakers to realize that English has a wider range of dative construction than French.

Inagaki (2001) addressed the issue of the overlap in the acquisition of motion verbs with goal prepositional phrases (PPs) by English and Japanese speakers. English permits two types of verbs to co-occur with goal PPs: the manner-of-motion verbs, such as walk and run and directed motion verbs, such as go as it is presented in (3). However, Japanese licenses the occurrence of the directed motion verbs only as in (4).

3. a. John walked to school

b. John ran into the house

c. John went to school (by) walking

d. John went into [or] entered the house (by) running

4. a.? * John-ga gakkoo-ni aruita

John-NOM shool-at walked

'John walked to school'

b.? * John-ga ie-no naka-ni hassita

John-NOM house-of indide-at ran

'John ran into the house'

c. John-ga gakkoo-ni aruit itta

John-Nom school-at walking went

'John went to school (by) walking'

b. John-ga ie-no naka-ni hasitte itta [or] haitta

John-Nom house-of inside-at running went [or] entered

'John went into (or entered) the house (by) running' 
Inagaki (2001) conducted a bidirectional study using a picture-based task in the form of an Acceptability Judgment Task to test the naturalness of these constructions in both languages. The hypothesis narrated that Japanese speakers will encounter no difficulty in acquiring constructions such as John walked to school as a grammatical English construction. This hypothesis is a result of the availability of positive evidence in the input in the course to acquire English manner-of-motion constructions. However, English speakers will fail to recognize that *John-ga gakkoo-ni aruita 'John walked to school' is impossible to speak in Japanese language. The lack of positive evidence allows English speakers to assume that they are possible constructions as they are in their L1, otherwise this construction is ungrammatical in the Japanese language. Results support the hypotheses and show that the Japanese speakers accept manner-of-motion verbs that occur with goal PPs as in the English example (3a). In contrast, English learners - including advanced level learners of Japanese accept the *John-ga gakkoo-ni aruita 'John walked to school' as a natural sentence in Japanese.

Extending this, Inagaki (2002) explored the superset/subset relation in the acquisition of English manner-of-motion verbs with ambiguous PPs by Japanese speakers. Inagaki (2002) examined if the Japanese speakers recognize the directionality of the prepositions under and behind when they co-occur with manner-of-motion verbs, such as walk, swim, etc. This study explains that in English, prepositions such as under and behind can give rise to an ambiguous interpretation in as in (5).

5. a. John swam (in a circular motion) under the bridge (locative)

b. John swam (at one point in his path being) under the bridge (direction)

On the other hand, Japanese just licenses the locative meaning of these prepositions, as it is illustrated in (6).

6. a. John-wa hasi-no sita-de oyoida

John-TOP bridge-GEN under-at swam

'John swam under the bridge' (locational only)

b. John-wa kabe-no usiro-de hasitta

John-TOP wall-GEN back-at ran

'John ram behind the wall'

Inagaki (2001) explained that Japanese learners face no difficulty with PPs, such as to, into and onto. One reason is because these prepositions are frequent in the input. Secondly, they are morphologically cued with an overt reflexive of a path. However, the results that predicts that Japanese learners will fail to recognize manner-of-motion verbs with the goal prepositions under and behind. This prediction is a result of the fact that (1) construction is infrequent in the input in comparison to unambiguous prepositions (to and into) and (2) Japanese learners will analyze this construction as denoting locative meaning only. A written picture-matching task results showed that Japanese learners failed to recognize the ambiguous readings of under and behind, despite the exposure to positive evidence in the input. Therefore, the study concluded that the existence of the positive evidence alone is insufficient to broaden L2 grammar and that positive evidence has to be robustly and frequently available in the input (Inagaki, 2001).

Similarly, Montrul (2001) investigated the acquisition of agentive verbs, such as march and walk with manner-of-motion structure by conducting a bidirectional study to examine Spanish and English speakers in the relative construction. Agentive verbs alternate transitively when they co-occur with PPs in English, such as The captain marched the soldiers to the tents vs. The soldiers marched. On the contrary, in Spanish language, this alternation is unacceptable ${ }^{*} E l$ general marchó a los soldados al campamento vs. Los soldados marcharon. Montrul (2001) examined if Spanish speakers will undergeneralize the given construction in English. The study observed if English speakers are able to overgeneralize the Spanish structure and showed that the picture judgment task support both types of generalization (Montrul, 2001). These results validated the argument previously presented by White (1991). Montrul (2001) suggested that Spanish speakers will overcome undergeneralization in learning English argument structure with exposure to positive evidence.

Few of the previous studies reported that negative evidence plays an essential role in learning L2 grammar (White, Carroll and Swain, 1993; Izumi \& Lakshmanan, 1998; Ellis, Loewen, \& Erlam, 2006; Kang, 2009). Izumi and Lakshmanan (1998) investigated the effect of the negative evidence of formal instruction on learning the English passive among the Japanese speakers as they are allowed direct and indirect passive. On the contrary, English only permits the direct passive. The result indicated that the performance of experiment group outperforms the control group who received no instruction on the target construction, after receiving an explicit instruction on the impossibility of indirect passive in English (Izumi \& Lakshmanan, 1998). 


\subsection{Instructions and Counterpart Learners}

VanPatten and Cadiernoa (1993) examined the explicit instruction in two types of instruction: a traditional form-focused instruction and a processing instruction. Traditional instruction takes the form of explaining and practicing the grammar. However, processing instruction provides explanation, learners' processing the input, and practicing. The results demonstrated that explicit instruction is effective on the level of comprehension and production for the group being exposed to the processing instruction. However, the traditional form-focused group is successful at the production level only. Another study by Li (2009) investigated the effects of explicit and implicit feedback of Chinese classifier on L2 Chinese learners L1 English, Korean, and Japanese at different levels of proficiency. The result indicated that explicit feedback is effective for low-proficiency learners, but not for high-proficiency learners. Likewise, Norris and Ortega $(2000,2001)$ compared 49 studies related to the effectiveness of L2 instruction. The results revealed that focused instruction leads to an increase of target-like structures in the performance of L2 learners and the explicit instructions are more effective than implicit ones.

Ellis (1989) found that the classroom learners are as their counterpart learners learning German word order in a naturalistic setting. Both groups follow the same pattern of acquiring complex grammatical features. However, the classroom learners have a tendency to be more successful in learning the relevant word order rapidly in a short period. Atay and Uygun (2010) investigated the effect of causative/inchoative alternation by L1 Turkish learners learning English as a second language. Turkish learners were assigned to three instruction groups: no instruction group, non-contrastive form-focused group instruction, and a contrastive form-focused instruction group. The results indicated that both explicit instruction groups perform better than the group, who received no instructions. Fotos (1993) addressed the issue of raising learners' consciousness of grammatical structures by examining the treatments of both the teacher-fronted grammar lesson and interactive grammar problems solving tasks. The task performance is equally as effective as the formal instruction. The study proves that learners notice the grammatical structures in communicative input after their consciousness is raised. Similarly, Schmidt (1994) observed the consciousness in input processing by examining subliminal learning, incidental learning, and implicit learning. Subliminal learning was examined in relation to noticing that the input consciously will lead to language learning; while, the incidental learning looks at paying attention consciously to the target structure in the process of learning. On the contrary, the implicit learning looks at whether the exposure to an input allows the learner to guess the target structure, consciously or unconsciously. The study concluded that the incidental learning is effective in focusing the learner's attention during the learning process (Schmidt, 1994). Ellis (2005) further claimed that language acquisition can be speeded up by explicit instruction without any focus on form or conscious raising formal accuracy.

\subsection{Directional Preposition 'to' with Manner-of-Motion Verbs in English and Arabic}

English has the directional preposition 'to' that denotes a movement with respect to a path towards a goal without involving boundary-crossing (henceforth B-C), as in (7).

\section{John ran to the school}

In this example, John moves to reach the goal (the school), but his final location does not involve being inside the school i.e. he does not cross the boundary to be inside the school. Pantcheva (2011) mentioned that the endpoint of John's path has the interpretation of at the school. On the contrary, the study suggests that 'the path can "continue" within the location'. Here, the path involves three components: a direction, a specified starting point, and a specified ending point (Pantcheva, 2011). However, Saeed (2014) assumed that every path does not necessarily imply the three elements as it depends on the preposition used in the event. For example, 'to' implies a direction and an end point in English. Accordingly, 'to' has the path type properties as follows:

\section{Cofinal (+ TRANSITIONAL, + ORIENTED, - DELIMITRD): to the school (Saeed 2014, p. 57)}

The 'transitional' component implies that the path has a 'transition from one spatial domain to a complementary spatial domain'. However, 'orientation' indicates the presence of direction conveyed by the directional preposition. On the contrary, delimitation specifies a terminative or the starting point in a path (Pantcheva, 2011). For the purpose of this study, delimitation type will be examined thoroughly. The example provided by Pantcheva (2011) states that the frog's path is directed towards the goal. Therefore, it has the feature of + TRANSITIONAL. In addition, the endpoint of the path is precisely specified to be in the lake. This argument makes it possible to assume that 'into' carries the feature of + DELIMITED.

9. The frog jumped into the lake

As far as the interpretation of English directional 'to' is concerned, the Arabic Pila (or li-) 'to' behave very much like English 'to'. It belongs to the goal category and has the properties in (10) as follows: 


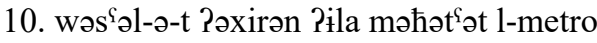

arrive-PST-3SG finally to station DEF-metro

'At last she arrived at the metro station (Note 2). (Saeed 2014, p. 58)

However, one point is absent in the reading of Pila in the observation by Saeed (2014), following Pantcheva's proposal. It is likely to assume that Pila implies an ambiguous terminative point, unlike English. Kabli (2013) proposed that Pila may involve B-C interpretation. Examining example (10), the common interpretation is that Pila implies that the entity reached the goal but does not exceed the boundary to be inside the station. The other possible interpretation is that the individual reaches and enters the station. To disambiguate the construction, an adverb of place is required to give rise to B-C interpretation following example illustrated from Saeed (2014, p. $61)$.

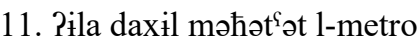

to inside station DEF-metro

'to inside the metro station'

Example (11) shows that Pila with the adverb of place 'inside' implies the interpretation of English directional preposition 'into'. This directional preposition and its counterpart 'onto' are absent in Arabic. Hence, Arabic speakers use adverb of place to convey the B-C meaning. Another alternative interpretation of B-C is deleting the directional preposition Pila optionally when it co-occurs with motion verbs with a path meaning (Saeed, 2014; Kabli, 2013), as in (12).

12. dəxəl-na (li-) l-ћədiqə

enter.PST-1PL to $\mathrm{DEF}^{- \text {garden }}$

'We entered the garden.' (Saeed 2014, p. 47)

Considering example (10), it is possible to argue that Pila carries the feature of \pm DELIMITED in Arabic. In this respect, the directional preposition ?ila 'to' is likely to behave differently from the English 'to'. It is likely to convey the interpretation of $\pm \mathrm{B}-\mathrm{C}$.

\subsection{Study Rationale}

Shedding light on the difference between English and Arabic in the realization of the directional prepositions, will make it possible to understand White (1991)'s proposal. According to White (1991), ?ila has a wider range of interpretation than the English 'to' (Figure 3). Thus, the partial fit between L1 and L2 will lead to a learnability problem. L2 learners will overgeneralize Pila in learning English ‘to'. They will treat 'to' as denoting the B-C interpretation as 'into'.

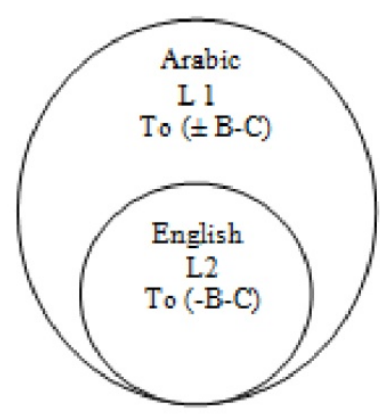

Figure 3. L1 is the superset and L2 is the subset

However, the situation is different in relation to English directional prepositions. English allows three types of directional prepositions 'to', 'into', and 'onto', unlike Arabic. Thus, English will occupy the position of the superset; while, Arabic is the subset (Figure 4). 


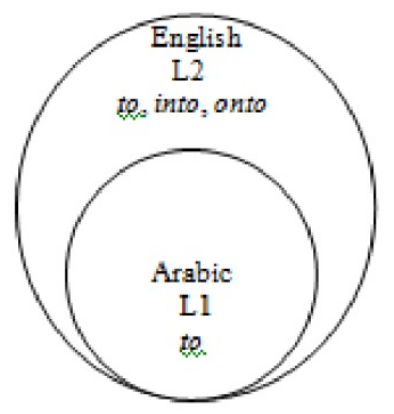

Figure 4. L2 is the superset and L1 is the subset

\section{Methods}

\subsection{Study Setting and Participants}

The study was conducted at an anonymous institute in Saudi Arabia. Four classes, with total 96 students joined in the pretest. Two classes were the included in the control group (C.G.); while, the remaining two classes were the experiment group (E.G.). Classes were assigned to each group, randomly. After pooling the number of students, many participants were excluded from the data. The exclusion criteria for this study were;

- Students, who missed the pretest or the posttest

- Students, who were absent during the instructional days

- Students, who had lived in an English community during their childhood

- Students, who selected one choice, leaving the other choices blank, were eliminated as well.

Based on these criteria, a total number of 26 students were enrolled in E.G. and 25 students in the C.G. C.G attended the normal instruction; while, the second group received 1-hour instruction on the target items. The C.G group learnt about English preposition without being provided any positive and negative evidences in the normal instruction. This was done to observe the result of extensive exposure of the target items instructed in class in the E.G. According to the bio-data questionnaire which accompanied the task, none of the students had ever lived or been exposed to the language in a native English-speaking community during their childhood. In addition, they were all monolingual speakers of Arabic and all were females. All participants had studied English formally in the classroom for 7 to 9 years. The average age of participants ranged between 19 to 20 years old. The institute, where the study took place used Online Oxford Placement to classify students according to their level. The European framework classified these students as a high B1and placed students in level 4 . The procedure adopted in teaching students is a communicative approach. Students received 18 hours of English instruction per week given by both native and non-native teachers.

\subsection{Study Materials}

\subsubsection{Questionnaire}

Acceptability Judgment Task (AJT) was developed to elicit participants' judgments on the task items. Students watched video clips on class projectors and marked their responses on the answer sheets. They selected their judgments based on three Likert scale ranges from completely acceptable to completely unacceptable with 'not sure' as a mid-point. The judgments were based on whether the items reflected the actual depicted motion in the video clips as an appropriate English interpretation. The 'not sure' option was used to determine if participants could not decide whether the task items were proper interpretation in English. The task was untimed since the clips were presented manually. Therefore, the presentation was controlled to provide no longer than one minute for each clip to ensure that students would not go back and forth to check their responses.

The task was divided into two main scenarios. Each scenario contained six target structures which were followed by two choices. The first scenario involved an entity that performs a motion without crossing the boundary, for example, a man swam to the cave, but he does not go inside it, as in (13). In contrast, the second scenario showed an entity that performed a motion and crossed the boundary, for example, a man swam into the cave, as in (14). The first choice had the directional preposition 'to'; while, the second choice had the directional preposition 'into'. The total numbers of target items were 12 items with 24 choices. The 11 remaining structures with their choices were distractors. These distractors were unrelated to the task and were excluded from the analysis. Examples of task items are presented below: 
1. Event involving no B-C animation clip

The man swam into the cave Acceptable Not Sure Unacceptable

The man swam to the cave Acceptable Not Sure Unacceptable

2. Event involving B-C animation clip

$\begin{array}{llll}\text { a. The man swam into the cave Acceptable Not Sure } & \text { Unacceptable } \\ \text { b. The man swam to the cave } & \text { Acceptable } & \text { Not Sure } & \text { unacceptable }\end{array}$

The task items with the choices were randomized randomly throughout the task. The task started by three distractors to ease the anxiety at the beginning of the task. Similarly, it ended by three distractors to avoid the factor of tiresome.

\subsubsection{Instructional Materials}

The E.G. received 1 hour of instruction for two consecutive days. In contrast, the C.G received no instruction on the target items and continued with their normal instruction. The instructional week took place a week after the pretest. Students received instruction on the directional prepositions to, into, and onto. In addition, they were exposed to locative prepositions in, on, under, behind and over. The locative prepositions were chosen because students were familiar with their structures and students should not encounter difficulty with learning prepositions, since they are available in their L1. Additionally, these prepositions would serve as fillers in the task items.

The instruction began by projecting the directional preposition slides. Students were requested to provide the counterparts of these PPs in their L1 to raise students' consciousness towards the relevant construction. Students were unable provide neither an equivalent nor a translation of the directional prepositions 'into' and 'onto' in their L1. Unlike locative prepositions, they could find a corresponding preposition in their L1 easily. The interpretation of each preposition was displayed by using animation clips in the power-point slides showing the differences between these prepositions. Students were asked to spot the difference between the direction preposition 'to' in one hand and the directional prepositions 'into' and 'onto' on the other using their own words. This allows students to process the difference in their input that raises the L2 learner's conscious in the relevant structure. After confirming that students were aware of the dissimilarity, seven video clips were displayed for directional prepositions as an activity. Students were requested to form a sentence with the appropriate preposition. The researcher replied 'That's correct' after each well-formed response. In case students supplied a wrong answer, the researcher kept silent with an expression of disapproval on her face or said 'No, that's incorrect'. Once the right answer spilt out, the researcher approved the answer by saying 'That's right!' or 'Yes, that's correct!', as follows:

Learner: The girl walked to the room

Researcher: No, not really

Learner: The girl walked through the room

Researcher: Through?! No, not through

Learner: (a few seconds silent) into, yes, into

Researcher: That's correct! (The well-formed construction appeared on the board)

In the above example, two types of evidence were involved. The learner's response was adjusted via negative evidence to control the overgeneralization of the directional preposition 'to'. Once the learner supplied the well-formed structure with 'into', the positive evidence was applied to broaden learner's grammar. On the same day, students were given a gap filling task to discuss the possible answers in pairs while displaying the video clips. In this task, the directional and locative prepositions were included. Students' responses were checked by means of correcting each other and explaining the reason to supply the given answer. In the case of supplying incorrect answers, students were informed that their responses were incorrect. Once another pair of students supplied the right answer, the research reacted by using the positive evidence. During the instructional session, it was guaranteed that the attention of the whole class was focused on the interaction.

The next day, past tense was introduced in relation with manner-of-motion verbs, such as fly, swim, crawl, jump, etc. The past tense was introduced because students had obtained prior knowledge of this tense in level 1 . Therefore, they reached the level which enabled them to master this type of tense. In addition, it was introduced with manner-of-motion verbs to avoid any misinterpretation of irregular verbs in the task, such as fly $=$ flew, run $=$ ran, swim $=$ swam. Instead of providing a translation of these verbs in the task, they were presented to students 
in advance during the construction. Students were given an activity to fill in the gap. They were requested to watch 10 animation clips. They were required to work in pair to supply the correct prepositions and the correct verb tense in the blanks based on what they saw in clips. Upon completing the task, the students discussed the answers together with the researcher. They were requested to correct each other and explain the reason for selecting certain construction.

\subsection{Procedure}

Class teachers informed their students briefly about the researcher's visit to their classes. On the day of the pretest, the researcher clarified the purpose of the study briefly and requested the classes to fill out the biodata on the first page of the questionnaire and sign the consent form prior to the administration. Upon completing the first page, students were requested to go to the second page of the task. Instructions of the task were read and were translated into Arabic to ensure that all students were fully aware of the questionnaire techniques. Two examples were provided to students for this purpose. The task was administrated by projecting the video clips one by one manually, after answering students' inquiries about the task and confirming that all students were ready. After each video clip, students were asked if they were ready to watch the next clip. A month later, the same task was run again after the experiment group received the instruction and the control group attended their usual classes.

\subsection{Data Analysis}

Statistical Package for the Social Sciences (SPSS) version 21 was used to analyze quantitative data after administration. Descriptive statistics for both groups on both sets of tests were measured. Test of reliability (Cronbach's alpha) presented a value of .658. However, a test of normal distribution revealed $p<.05$. Therefore, non-parametric tests were chosen for data analysis. The Mann-Whitney test measured the performance of both groups in the one type of item. For example, it is used to measure the performance of the E.G. and the C.G. on the directional preposition 'to' without boundary-crossing event. Furthermore, the Wilcoxon compared the performance of the individual group before and after instruction, along with comparing two sets of test items in each group.

\section{Results}

Table 1 indicates the overall percentage scores of participants' judgments on the target items. Items in the same category were calculated together and were rated based on the participants' acceptable judgments.

Table 1. Pretest/posttest acceptable judgments of the E.G. and the C.G. in percentages

\begin{tabular}{ccccc}
\hline & \multicolumn{2}{c}{ Experiment Group (E.G.) } & \multicolumn{2}{c}{ Control Group (C.G.) } \\
\hline Type of Items & Pretest & Posttest & Pretest & Posttest \\
+ B-C + to & $55 \%$ & $3 \%$ & $57 \%$ & $51 \%$ \\
- B-C + to & $83 \%$ & $88 \%$ & $66 \%$ & $67 \%$ \\
+ boundary + into & $78 \%$ & $98 \%$ & $62.66 \%$ & $60 \%$ \\
- boundary + into & $39 \%$ & $13 \%$ & $30 \%$ & $29 \%$ \\
\hline
\end{tabular}

4.1 Preliminary Analysis

The above table shows that Saudi Arabic speakers accept 'to' with and without B-C in the pretest as is the case in their L1. The E.G. rated 'to' with B-C as 55\% in comparison to 57\%. Similarly, the E.G. judged $83 \%$ for 'to' without B-C while the C.G. gave judgments of $66 \%$ of all cases. However, the gap in the posttest is increased between the two groups, after the E.G. receives the negative evidence on 'to' with B-C construction. The E.G. gave judgment of $3 \%$ in the posttest in comparison to $55 \%$ in the pretest. E.G.'s rating on this construction in the posttest was higher than the pretest ( $83 \%$ vs. $88 \%$ ), despite the fact that both groups accept 'to' without B-C construction in the pretest as this construction is similar to their L1. In contrast, the performance of the C.G. remains constant in this construction (66\% vs. $67 \%$ ).

In light of table 1, both experimental groups allow the construction of B-C with 'into' in the pretest. The E.G. gave tokens of $78 \%$ of all cases; whereas, the C.G. supplied them in $62.66 \%$ of the cases. The E.G.'s performance in the posttest shows an increase of acceptance of proper English construction of among $98 \%$ of the cases. However, the performance of the C.G. remains in the range of $60 \%$. For construction that does not involve B-C with 'into' in the pretest, both groups produce low judgments. The E.G. and C.G. gave acceptable judgments of $39 \%$ and $30 \%$ of all cases, respectively. The posttest reveals that the E.G.'s ratings were lower than $39 \%$ (E.G. $=$ $13 \%$ ). In contrast, the control groups' performance remained stable (30\% vs. 29\%). 
A comparison was drawn between the L2 learner groups to examine if there was any significant difference related to participants' judgments on 'to' vs. 'into' with B-C event. According to table 1, the E.G. supply very low acceptable judgments in 'to' with B-C event (3\%) in comparison to 'into' with B-C event $(98 \%)$ in the posttest. In contrast, the control group accepted both interpretations (51\%-60\%).

\subsection{Results of $\pm B-C$ with 'to'}

An inferential statistic was run to determine if there are significant differences on $\pm \mathrm{B}-\mathrm{C}$ with 'to' for the two groups. The Mann-Whitney test shows no significant difference between groups in the pretest $(p$. $>.05)$. However, Mann-Whitney test comparing the performance of two groups in the posttest showed that there was a significant difference between the E.G. and the C.G. in the B-C event with 'to' construction $\left(U=41.000, N_{1}=26\right.$, $N_{2}=25, p=.000$, two tailed).

Wilcoxon test revealed a significant difference in the performance of the E.G. on 'to' with B-C construction $(z=$ $4.301, N$ - Ties $=2, p .000$ ) to compare the performance of an individual group before and after the exposure to the negative evidence. Nevertheless, no significant difference was found in the performance of the E.G. in the relevant construction nor in the performance of the C.G. as in both expressions $(p>.05)$.

\subsection{Results of $\pm B$ - $C$ with 'into'}

According to the Mann-Whitney test for \pm B-C with 'into', there was a non-significant difference in the performance of both groups in the pretest as $(p>.05)$. Visual comparisons of the performance of both groups in $\pm \mathrm{B}-\mathrm{C}$ with 'into' are presented in table 5 and 6 . The Mann-Whitney test was run on \pm B-C with 'into', which revealed significant differences between the two groups in the posttest when the event involves boundary-crossing with 'into' $(\mathrm{U}=80.000, \mathrm{~N} 1=26, \mathrm{~N} 2=25, \mathrm{p}=.000$, two tailed $)$ and in the event without B-C and 'into' $(\mathrm{U}=202.000, \mathrm{~N} 1=26, \mathrm{~N} 2=25, \mathrm{p}=.013$, two tailed).

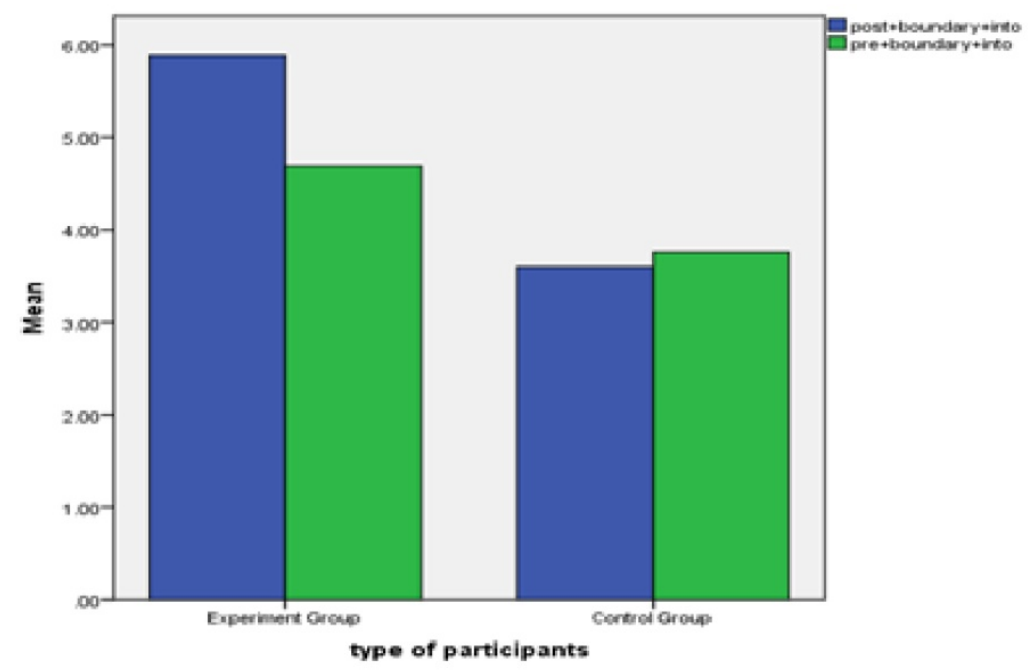

Figure 5. A comparison between the E.G. and the C.G. in the construction involves B-C with 'into' 


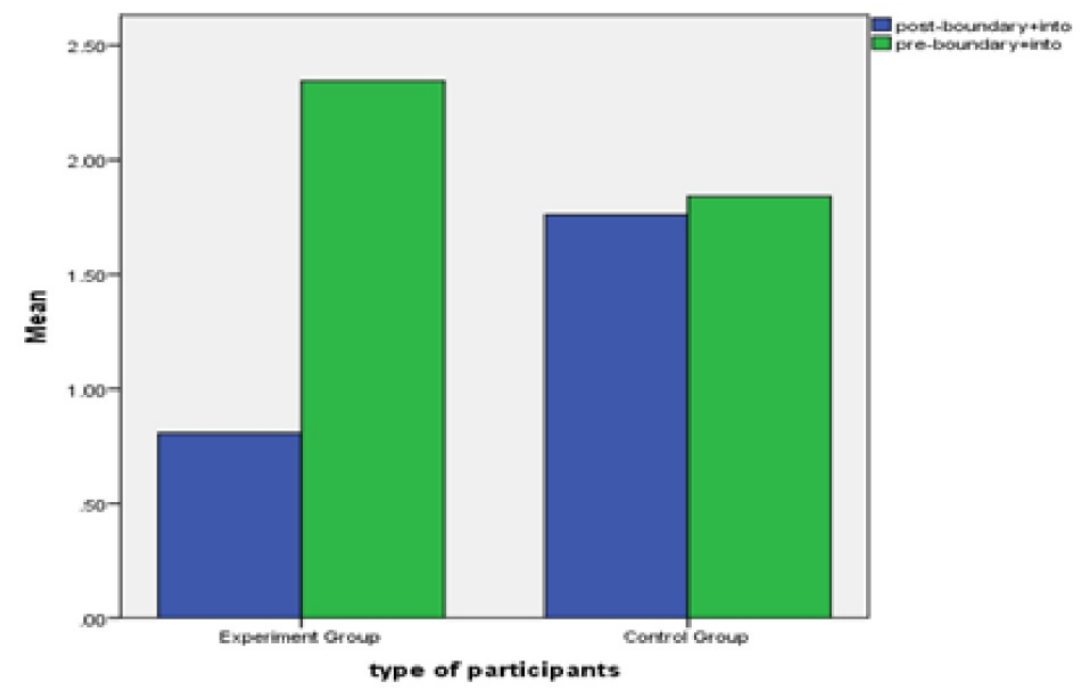

Figure 6. A comparison between the E.G. and the C.G. in the construction does not involve B-C with 'into' 4.4 Results of + to vs. + into with $B-C$

Wilcoxon test was administrated to examine significant difference in the performance of the E.G. and the C.G. in the posttest in their judgments on 'to' versus 'into'. The test revealed a significant difference in the performance of the E.G. group $(z=4.720, N-$ Ties $=0, p .000)$. On the contrary, the test shows no significant difference in the performance of the C.G. as $p$ is .369. The visual comparison between the two groups in the test items is presented in figure 7.

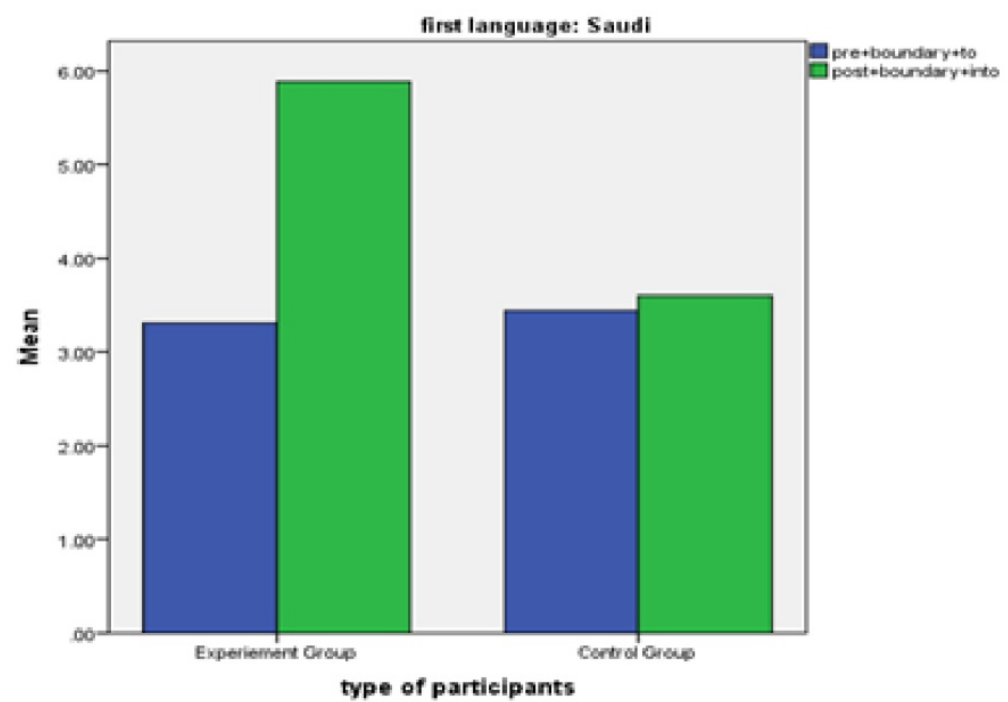

Figure 7. A comparison between the E.G. and the C.G. of 'to' vs. 'into' in the event involves B-C in the posttest

\section{Discussion}

The first research question examined if both groups overgeneralize English 'to' as denoting \pm B-C interpretations in the pretest. The inferential statistics show that both groups of Saudi speakers transfer the property of the L1. They evaluate 'to' as denoting the same interpretation with and without B-C. The second research question determined if the negative evidence helps the E.G. to restrict their grammar according to L2 grammar in the posttest. The result indicated that the E.G. starts to limit their grammar to that of the L2. A significant difference was found between the two groups in 'to' with B-C in the posttest. This outcome provided a positive answer and supports Ellis (1989) finding that classroom learners are more successful in learning L2 structures rapidly and in a short time. It also supported Ellis (2005) proposal that explicit instruction will speed up the acquisition by focusing on the form and consciences raising. Likewise, a significant difference is found between the two groups in construction without B-C and 'to' in the posttest. This difference is due to an increased knowledge of this 
construction as being acceptable structure in English, in addition to L1 transfer.

The third research question observed if positive evidence is an effective treatment to broaden the E.G. group's grammar. Both groups demonstrated the acquisition of this property at this level of proficiency. Kabli (2013) suggested that the availability of similar property in the L1 facilitate the acquisition of a new construction in the L2. Saudi Arabic intermediate level of proficiency speakers showed early acquisition of the directional prepositions into and onto. In addition, the directional prepositions 'into' and 'onto' were frequent in the input and were morphologically cued (Inagaki, 2001; Inagaki, 2002). The plausible explanation is that students are exposed generally to positive evidence when they are instructed in the classroom. This finding is supported by White (1991) that positive evidence is a beneficial treatment to broaden L2 learners' grammar, when the L1 is the subset of the L2. In addition, Montrul (2001) mentioned that 'if a learner posits a more restrictive grammar to start with, positive evidence in the input would always be available, leading the learner to eventually notice that a wider grammar is possible in the L2. Moreover, learners benefit from the explicit feedback at this stage of proficiency level in learning the impossibility of the directional preposition 'into' without B-C as suggested by $\operatorname{Li}(2009)$.

The fourth research question addressed the issue of difference in the judgments of 'to' and 'into' for both groups in the event depicting B-C after the E.G. received positive evidence. The statistics revealed significant difference in the performance of the E.G. in this type of construction in the posttest. This finding is due to the exposure to the positive evidences in the classroom. The E.G. is eventually aware of the requirement of the directional preposition 'into' with B-C event. This was further supported by White (1991) as the study stated that positive evidence assists L2 learners to acquire a new property. These results prove that the E.G. benefits from the positive evidence, indicating that the lack of exposure to positive and negative evidence leads the C.G. to accept the ungrammaticality of 'to' with B-C.

The study has provided suggestions on EFL teaching or English writing course design as it leads to the development of EFL teaching and learning. The teachers need to consider adaptation of different materials for diverse learners to present guidelines to design effective materials for teaching and learning English. Although, design of teaching materials in the teacher education process cannot be considered as the solution for all challenges, but it can convey some inspiring contribution in the planning, designing, and redesigning of teaching practices. In EFL classroom, teacher need to spend time in maintaining balance between the writing and other communication skills to emphasize on linguistic skills such as planning and drafting, pre-writing with brainstorming. The benefits and difficulties experienced by the learners are likely to be understood by analyzing the perspectives of the students participating in such a writing course to get help in course.

The present study has investigated the effect of L1 in learning L2 directional prepositions related to manner-of-motion to goal constructions. It examined the negative evidence role in learning the English directional preposition 'to'. In addition, it studied the positive evidence effect in the learning English directional preposition 'into'. The results conclude that negative and positive evidence were effective techniques in the classrooms that supported the argument presented by White (1991). The findings of this study demonstrate that L2 learners are able to restrain the overgeneralization of 'to' with B-C event via negative evidence. Similarly, positive evidence helps the E.G. learners to broaden their L2 argument structures far more in the posttest in learning 'into' with B-C. The E.G. provide clear evidence of an increased awareness to differentiate between 'into' and 'to' in the event depicting B-C event. Interestingly, both negative and positive evidence enable the E.G. to increase the awareness of the requirement of 'into' with B-C event and limit the overgeneralization of 'to' in similar argument structure. As with all studies in the classrooms, there are a few limitations in this investigation. One limitation of the study is lack of qualitative data to enable students to express their point of views concerning these constructions by selecting students randomly for interviews. To counteract this, an open question at the end of the task is recommended, so that students can express themselves and obtain more information on the target items. The period between the pre- and the post-test is relatively short. It is desirable if students are exposed to posttest after several months to measure the effectiveness of these techniques. This will ensure if students have established L2 structures in their grammar in the long-term. However, due to the fact that the institute adopts the modular system, it is difficult to recruit the same students after the graduation from the foundation year. Several questions remain open and require further investigation with respect to manner. For instance, future studies need to focus on the impact of using animation clips, which is not focused in the present study.

\section{Acknowledgement}

The researcher expresses her gratitude to the anonymous institute and all students who participated in the study. 


\section{References}

Atay, D. \& Uygun, D. (2010). Differential effects of instruction on Turkish EFL learners' acquisition of causative/inchoative alternation. In International Conference on New Trends in Education and Their Implications (pp. 741-46).

Cabrera, M. \& Zubizarreta, M. L. (2003). On the acquisition of Spanish causative structures by L1 speakers of English. Proceedings of the 2002 Generative Approaches to Second Language Acquisition (GASLA-6), L2 Links, 24-33.

Cabrera, M. \& Zubizarreta, M. L. (2005). Overgeneralization of causatives and transfer in L2 Spanish and L2 English. In Selected Proceedings of the 6th Conference on the Acquisition of Spanish and Portuguese as First and Second Languages (pp. 15-30). Somerville, MA. Cascadilla Press.

Carroll, S. \& Swain, M. (1993). Explicit and implicit negative feedback: An empirical study of the learning of linguistic generalizations. Studies in second language acquisition, 15(3), 357-386. https://doi.org/10.1017/s0272263100012158

Ellis, N. C. (2005). At the interface: Dynamic interactions of explicit and implicit language knowledge. Studies in second language acquisition, 27(2), 305-352. https://doi.org/10.1017/s027226310505014x

Ellis, R. (1989). Are classroom and naturalistic acquisition the same? A study of the classroom acquisition of German word order rules. Studies in second language Acquisition, 11(3), 305-328. https://doi.org/10.1017/s0272263100008159

Ellis, R., Loewen, S. \& Erlam, R. (2006). Implicit and explicit corrective feedback and the acquisition of L2 grammar. Studies in second language acquisition, 28(2), 339-368. https://doi.org/10.1017/s0272263106060141

Fotos, S. S. (1993). Consciousness raising and noticing through focus on form: Grammar task performance versus formal instruction. Applied linguistics, 14(4), 385-407. https://doi.org/10.1093/applin/14.4.385

Inagaki, S. (2001). Motion verbs with goal PPs in the L2 acquisition of English and Japanese. Studies in Second Language Acquisition, 23(2), 153-170. https://doi.org/10.1017/s0272263101002029

Inagaki, S. (2002). Japanese learners' acquisition of English manner-of-motion verbs with locational/directional PPs. Second Language Research, 18(1), 3-27. https://doi.org/10.1191/0267658302sr196oa

Izumi, S. \& Lakshmanan, U. (1998). Learnability, negative evidence and the L2 acquisition of the English passive. Second Language Research, 14(1), 62-101. https://doi.org/10.1191/026765898675700455

Jabbari, A. A. \& Niroomizadeh, A. K. (2008). The effect of negative and positive evidence on learning English as a foreign language by Persian speakers. Pazhuhesh-e Zaban-haye Khareji (Research on Foreign Languages), 51, 45-61. https://doi.org/10.20988/lfp.2015.35..65

Juffs, A. (2000). An overview of the second language acquisition of links between verb semantics and morpho-syntax. Second language acquisition and linguistic theory, 170-179.

Kabli, H. (2013). The acquisition of English manner-of-motion to goal construction and resultative change-of-state construction by L2 speakers with L1 Saudi Arabic and L1 German. Unpublished doctoral thesis, University of Essex.

Kang, H. S. (2009). The relative efficacy of explicit and implicit feedback in the learning of a less-commonly-taught foreign language. IRAL-International Review of Applied Linguistics in Language Teaching, 47(3-4), 303-324. https://doi.org/10.1515/iral.2009.013

Li, S. (2009). The differential effects of implicit and explicit feedback on second language (L2) learners at different proficiency levels. Applied Language Learning, 19(1), 53-79.

Long, M. (1996). The role of the linguistic environment in second language acquisition. Handbook of second language acquisition.

Marcus, G. F. (1993). Negative evidence in language acquisition. Cognition, 46(1), 53-85. https://doi.org/10.1016/0010-0277(93)90022-n

Montrul, S. (2001). Agentive verbs of manner of motion in Spanish and English as second languages. Studies in Second Language Acquisition, 23(2), 171-206. https://doi.org/10.1017/s0272263101002030

Montrul, S. A. (1997). English, Spanish and Turkish (Doctoral dissertation, McGill University, Montreal). 
Moore, M. M. P. (1994). Second language acquisition of lexically constrained transitivity alternations: Acquisition of the causative alternation by second language learners of English.

Norris, J. M. \& Ortega, L. (2000). Effectiveness of L2 instruction: A research synthesis and quantitative meta-analysis. Language learning, 50(3), 417-528. https://doi.org/10.1111/0023-8333.00136

Norris, J. M. \& Ortega, L. (2001). Does type of instruction make a difference? Substantive findings from a meta-analytic review. Language learning, 51, 157-213. https://doi.org/10.1111/j.1467-1770.2001.tb00017.x

Pantcheva, M. B. (2011). Decomposing path: The nanosyntax of directional expressions.

Saeed, S. A. M. E. E. R. A. H. (2014). The syntax and semantics of Arabic spatial PS. NEWCASTLE AND NORTHUMBRIA WORKING PAPERS IN LINGUISTICS VOLUME, 20, 2014, 44.

Schmidt, R. (1994). Deconstructing consciousness in search of useful definitions for applied linguistics. Consciousness in second language learning, 11, 237-326.

White, L. (1987). Markedness and second language acquisition: The question of transfer. Studies in Second Language Acquisition, 9(3), 261-285. https://doi.org/10.1017/s0272263100006689

White, L. (1990). Second language acquisition and universal grammar. Studies in second language acquisition, 12(2), 121-133. https://doi.org/10.1017/s0272263100009049

White, L. (1991). Argument structure in second language acquisition. Journal of French Language Studies, 1(2), 189-207. https://doi.org/10.1017/s0959269500000983

White, L. (2003). Fossilization in steady state L2 grammars: Persistent problems with inflectional morphology. Bilingualism: language and cognition, 6(2), 129-141. https://doi.org/10.1017/s1366728903001081

\section{Appendix}

Words used for practicing English Writing

give, book, walk, run, school, swim, behind, wall

jump, lake, inside, station, enter, garden,

cave, room

Notes:

Note 1.

Note 2. The preposition 'at' is used here to indicate that the interpretation of this sentence reflects the absence of crossing the boundary in the ending point. It reflects the meaning in the Arabic transliteration in one variant of 'to'. For the purpose of this study, I would rather prefer to replace 'at' with 'to' to clarify the argument.

\section{Copyrights}

Copyright for this article is retained by the author(s), with first publication rights granted to the journal.

This is an open-access article distributed under the terms and conditions of the Creative Commons Attribution license (http://creativecommons.org/licenses/by/4.0/). 